\title{
Gender of Physician as the Usual Source of Care and Patient Health Care Utilization and Mortality
}

\author{
Anthony Jerant, MD, Klea D. Bertakis, MD, MPH, Joshua J. Fenton, MD, MPH, \\ and Peter Franks, MD
}

Background: Practice styles differ by provider gender, but whether provider gender influences health care utilization and mortality is unknown. The objective of this study was to examine associations of the gender of a patient's usual source of health care (USOC) with health care utilization and mortality.

Methods: This was a prospective observational study employing data from respondents aged $\geq 18$ years entering the 2002 to 2008 United States Medical Expenditure Panel Surveys, reporting a USOC at entry, and participating for 2 years $(N=21,365)$. Analyses examined the association of gender of the USOC in survey participation year 1 with the following health care utilization outcomes in participation year 2: total health care expenditures, prescription drug expenditures, and number of office visits (Poisson regressions) and having more than one emergency visit and more than one hospitalization (logistic regressions). A Cox regression examined survival (ascertained via linkage with the National Death Index) through 2006 for the subset of respondents enrolled from 2002 to $2006(\mathrm{n}=11,328)$. All analyses were adjusted for respondent sociodemographic and health characteristics and USOC specialty and race/ethnicity.

Results: Reporting a female USOC was associated with being younger, female, and urban. There were no significant adjusted associations of female USOC status with total expenditures (parameter estimate of increase [PE], 4.56\%; 95\% confidence interval [CI], -3.04 to 12.76), prescription expenditures (PE, $3.33 \%$; 95\% CI, -4.32 to 11.59), number of office visits (PE, $1.28 \%$; 95\% CI, -3.30 to 6.08), having more than one emergency visit (odds ratio, 0.98 ; 95\% CI, 0.87-1.11), having more than one hospitalization (odds ratio, 0.98 ; 95\% CI, 0.87-1.11), or mortality (hazard ratio, 0.94; 95\% CI, 0.64-1.38).

Conclusions:Gender of the USOC was not associated with health care utilization or mortality. These findings suggest reported gender of the USOC may not have nationally important effects on health care utilization and mortality. (J Am Board Fam Med 2013;26:138-148.)

Keywords: Gender, Health Expenditures, Health Personnel, Mortality, Primary Health Care

Studies have demonstrated key differences in practice styles by gender of health care providers, with potential implications for patient health care use and mortality. For example, female physicians consistently have been found to employ a more patient-centered communication style, devoting more time to elements

This article was externally peer reviewed.

Submitted 27 July 2012; revised 8 October 2012; accepted 23 October 2012.

From the Department of Family and Community Medicine, Center for Healthcare Policy and Research, University of California Davis School of Medicine, Sacramento, CA.

Funding: none.

Conflict of interest: none declared.

Corresponding author: Anthony Jerant, Department of Family and Community Medicine, University of California Davis School of Medicine, 4860 Y Street, Suite 2300, Sacramento, CA 95817 (E-mail: afjerant@ucdavis.edu). such as psychosocial counseling, social exchange, pursuing active partnership, and providing encouragement and reassurance. ${ }^{1-4}$ In turn, more patient-centered physician communication has been associated with lower health care use and expenditures. ${ }^{5-7}$ Other studies have found that female physicians are more likely than men to provide certain morbidity- and mortality-reducing preventive services to women (eg, Papanicolaou testing, mammography). ${ }^{8-11}$ Additional group studies, albeit with more mixed findings, have found some process of care outcomes to be more favorable for female versus male physicians. ${ }^{12-14}$ Some of the process outcomes examined in these latter studies (eg, prescription of $\beta$-blockers for heart failure, optimizing blood pressure in type 2 diabetes) have been associated with health care use and mortality. ${ }^{15-18}$ 
Taken as a whole, these findings suggest potential associations between female gender of providers and lower patient health care use and mortality. Elements of patient-centered communication exhibited more often by female providers during office visits, such as thorough elicitation of patient concerns and more optimal responses to elicited concerns (eg, probing for meaning rather than reflexive ordering of tests), may lead to lower health care use and expenditures for patients of female physicians. However, there is also the potential for more complex, competing influences of provider gender on use and mortality, with uncertain net effects. For example, with regard to office visits, more thorough elicitation of and addressing patient concerns by female providers might serve to reduce referral visits to specialists driven by unmet patient expectations, ${ }^{5}$ but it might also empower some patients to schedule additional visits with the primary care provider to discuss previously neglected health concerns that may be difficult to discuss (eg, taboos). Such observations underscore the need for empirical studies examining the net independent associations of provider gender with heath care use and mortality in the United States.

We analyzed longitudinal data from a nationally representative sample of respondents entering the 2002 to 2008 U.S. National Medical Expenditure Panel Surveys (MEPS) to determine the associations between the gender of the respondent's usual source of health care (USOC) and subsequent health care use (office visits, emergency department visits, hospitalizations) and expenditures (prescription drugs and total). Via linkage of MEPS data with the National Death Index (NDI) through December 31, 2006, we also examined the association of USOC gender with all-cause mortality. All analyses were adjusted for patient and physician characteristics that may affect health care use and mortality.

\section{Methods}

The MEPS is an annual national survey of health care use and costs among the U.S. civilian, noninstitutionalized population and employs an overlapping panel design. ${ }^{19}$ Individual data are collected through 6 interviews over a 2-year period. All respondents answer a question asking whether they had a USOC in the past year (yes/no), defined as a particular medical professional, doctor's office, clinic, health center, or other place they went if sick or needing advice about their health. Those answering yes then were asked the gender of their USOC. The analytic sample for the current study included adults 18 years and older self-reporting a USOC at entry and participating for 2 years.

The MEPS Household Component (HC) includes information on respondents' self-reported health care features, sociodemographics, health insurance, and USOC characteristics. A self-administered questionnaire in both MEPS participation years includes items on chronic health conditions and health status. The full-year response rate varied from $64.4 \%$ to $69.2 \%$ for the panels of data we used. ${ }^{19}$

The MEPS HC is a subsample of households included in the previous year's National Health Interview Survey (NHIS), conducted annually by the National Center for Health Statistics. The NHIS is linked to death certificate data in the NDI, a central computerized index of U.S. death record information on file in state vital statistics offices; this permitted linkage to the MEPS. ${ }^{20}$

\section{Measures \\ Health Care Use (Year 2)}

During each survey round, the MEPS also collects detailed information about health service use, including office and emergency department visits, inpatient hospitalizations, and prescription drug use. Self-reported health care use is validated and verified by standardized medical record abstraction among a subsample of respondents. The MEPS also ascertains from respondents and physicians the sum of insurance payments and out-of-pocket costs for services received. We used these data to specify the total number of office visits, emergency department utilization ( $\geq 1$ visit), hospital admissions ( $\geq 1$ admission), prescription drug expenditures, and total health care expenditures in year 2 .

Mortality was assessed via the NDI with the public-use version of the NHIS-linked mortality files. ${ }^{20}$ Calibration studies indicate that, overall, $98.5 \%$ of respondents are correctly classified by their death date or as alive. ${ }^{20}$ Survival was measured in quarters from the time of the health measure self-assessment until the time of death; it was considered censored if the respondent was alive on December 31, 2006. 


\section{Patient Covariates}

The patient sociodemographic, attitudinal, and health measures described below were measured in the first year of MEPS participation for each individual. These were included as covariates in the analyses given their associations with health care utilization and mortality in prior studies. ${ }^{21-38}$

Sociodemographic measures (self-reported) included age (years); sex; race/ethnicity (Hispanic [any race], non-Hispanic White, non-Hispanic black, non-Hispanic other); household income level $(<100 \%, 100 \%$ to $124 \%, 125 \%$ to $199 \%$, $200 \%$ to $399 \%$, or $\geq 400 \%$ of the Federal poverty level); education level ( $0-8$ years formal schooling [less than high school]; 9-11 years [some high school]; 12 years [high school graduate]; 13-15 years [some college]; $\geq 16$ years [college graduate]); U.S. Census region of residence (West, Midwest, Northeast, South); and urbanicity (living in a metropolitan statistical area or not). Health insurance status was also self-reported, with respondents classified as uninsured (no insurance for the whole year), privately insured (any private insurance during the year), or publicly insured (only public insurance during the year).

Respondent skepticism toward medical care was assessed with a previously constructed and validated 4-item measure (do not need health insurance; insurance not worth the cost; more likely to take risks than the average person; can overcome illness without medical help), employing a 5 -point response scale $(1=$ disagree strongly, $5=$ agree strongly). ${ }^{23,24}$ Individual item responses were summed and rescaled to a score of 1 to 5 (a higher score equals greater skepticism; Cronbach $\alpha$ in the current sample $=0.67$ ).

Several health measures also were included. Health status was measured each year with the 12-item Short Form Physical Component Summary (PCS) and Mental Component Summary (MCS) scores (range, 0-100; higher scores equal better health). ${ }^{39}$ Global self-rated health was measured with a single item, which asked, "In general, would you say your health is: excellent, very good, good, fair, or poor?" Respondents also self-reported the presence (yes/no) of 8 chronic health conditions: diabetes, hypertension, coronary heart disease, myocardial infarction, cerebrovascular disease, asthma, emphysema, and arthritis.
Self-reported smoking status was dichotomized as current smoker or not. Body mass index (BMI) in kilograms per meters squared was constructed from self-reported height and weight. BMI categories employed in analyses were $<20$ (underweight); 20 to $<25$ (normal weight); 25 to $<30$ (overweight); 30 to $<35$ (obese); and $\geq 35$ (severely obese). ${ }^{25}$

\section{USOC Covariates}

Besides gender, 2 additional USOC characteristics assessed in the MEPS were included in our models, given research evidence they may affect health care use $^{40-42}$ : specialty (family medicine or general practice, general internal medicine, or subspecialist) and race/ethnicity (dichotomized in this study as non-Hispanic white vs other).

\section{Data Analysis}

Data were analyzed using STATA version 12.1 (Stata Corp., College Station, TX), adjusting for the complex survey design of MEPS. Data were analyzed using longitudinal strata and primary sampling unit identifiers and survey weights to derive estimates representative of the U.S. civilian, noninstitutionalized, adult population.

Logistic regression was used to examine the adjusted associations between respondent and USOC characteristics (independent variables) and report of having a female USOC (dependent variable). A series of Poisson regressions were used to determine associations between gender of the USOC (the key independent variable) and total health care expenditures, prescription drug expenditures, and number of office visits. Adjusted parameter estimates (APEs) from Poisson models of expenditures and office visits can be used to approximate percentage differences for a unit change in the independent variable (or in relation to the reference category) using the formula: \% Difference = $[\exp (\mathrm{APE})-1]^{*} 100$. A series of logistic regressions were used to examine associations between gender of the USOC (key independent variable) and emergency department use $(>1$ emergency visit) and hospital utilization ( $>1$ hospitalization). Cox regression was used to examine the associations between USOC gender and all-cause mortality through 2006 (the latest year for which NDI mortality data were available) for the subset of respondents enrolled from 2002 to 2006. The proportional hazards assumption was examined in the Cox regression both graphically and 
statistically, and no substantial evidence of violation was found.

The following patient covariates were included in all models: age; gender; race/ethnicity category (reference $=$ non-Hispanic white); education category (reference $=$ less than high school); household income (reference $=<100 \%$ of Federal poverty level); Census region (reference $=$ Northeast); urbanicity (residence in metropolitan statistical area vs not); health insurance status (reference $=$ privately insured); physical and mental health status (PCS and MCS scores, respectively); self-rated health (reference $=$ excellent); health conditions (count of 8 chronic conditions); BMI (reference = $<20 \mathrm{~kg} / \mathrm{m}^{2}$ ); smoker (yes vs no); and skepticism toward medical care. USOC covariates included in all models were specialty (reference $=$ family medicine/general practice) and race/ethnicity (nonHispanic white vs other). All analyses also were adjusted for MEPS panel year (to account for secular trends).

We also performed 2 sets of supplementary analyses to further characterize the relationship of gender of the USOC with study outcomes. The first set examined whether the associations of USOC gender with the study outcomes would be more evident among respondents reporting the same USOC gender in both years. These analyses employed the same regression models used in the primary analyses but were limited to examining to respondents reporting the same USOC gender in both survey participation years $(\mathrm{n}=15,722)$. The second set of supplementary analyses examined whether a change in utilization outcome from the first to the second year of survey participation was associated with a change in USOC gender. These analyses were included because some patients might have changed to a USOC of the opposite gender because of dissatisfaction with the gender of their original USOC, and patient satisfaction has been associated with health care use. ${ }^{43}$ These analyses (fixed effects panel data or "difference in differences" approach) employed conditional logistic regression for the changes in emergency and hospitalization outcomes and linear regression for the changes in expenditures and office use associated with changing USOC gender (the key independent variable). ${ }^{44,45}$ In this approach, variables that are unchanged from year to year (including unmeasured confounders) do not affect parameter estimation.

\section{Results}

There were 25,743 eligible adults aged 18 to 90 years entering the MEPS cohorts between 2002 and 2008 and reporting the gender of their USOC. Of these, 21,365 (83.0\%) had complete baseline data and were included in the analyses of health care use. Among the 11,328 participants with ascertained mortality through 2006, 340 (3\%) died during follow-up.

\section{Associations of Year 1 Patient and USOC Characteristics with Year 1 USOC gender}

Table 1 shows unadjusted (univariate) associations of baseline characteristics of the study sample with USOC gender. Compared with respondents reporting a male USOC, respondents with a female USOC were younger, more likely to be female, have non-Hispanic black or other race/ethnicity, have graduated college, live in an urban area, have normal or low BMI, and be a nonsmoker. More female than male USOCs were reported to be generalists and of racial/ethnic minorities.

As shown in Table 2, most but not all the univariate associations persisted in adjusted cross-sectional analyses. After adjustment, reporting a female USOC was associated with patients being younger, female, and urban. Female USOCs were less likely than male USOCs to be non-Hispanic white. There was also a temporal trend for USOC gender: respondents were more likely to report having a female USOC in more recent panel years.

\section{Associations of Year 1 Patient and USOC Characteristics with Year 2 Health Care Use}

Table 3 shows unadjusted (univariate) associations of measures of health care use with gender of the USOC. For each of the usage measures, values were similar for female versus male USOCs. Table 4 shows the results of analyses examining adjusted associations of patient and USOC characteristics with total health care expenditures. Patient characteristics associated with higher total expenditures were older age, higher education level, and having less than excellent health status. Patient characteristics associated with lower total expenditures were Hispanic ethnicity (any race) and non-Hispanic other race/ethnicity (vs non-Hispanic white race/ethnicity), having public or no health insurance (vs private insurance), higher physical and mental health status, and greater skepticism toward medical care. Regarding USOC characteristics, being 
Table 1. Baseline Characteristics of the Study Sample by Gender of the Usual Source of Care (USOC) $(\mathrm{N}=21,365)$

\begin{tabular}{|c|c|c|}
\hline \multirow[b]{2}{*}{ Characteristics } & \multicolumn{2}{|c|}{ Gender of the USOC } \\
\hline & $\begin{array}{c}\text { Male } \\
(\mathrm{n}=16,896)\end{array}$ & $\begin{array}{c}\text { Female } \\
(\mathrm{n}=4469)\end{array}$ \\
\hline Percent of total sample & 79.1 & 20.9 \\
\hline \multicolumn{3}{|l|}{ Patient characteristics } \\
\hline Age, yr & $51.7(0.2)$ & $48.8(0.4)$ \\
\hline Female & $50.0(0.4)$ & $70.8(0.7)$ \\
\hline \multicolumn{3}{|l|}{ Race/ethnicity } \\
\hline Hispanic (any race) & $8.1(0.4)$ & $8.1(0.5)$ \\
\hline \multicolumn{3}{|l|}{ Non-Hispanic } \\
\hline White & $77.4(0.7)$ & $73.6(0.9)$ \\
\hline Black & $9.0(0.4)$ & $11.3(0.6)$ \\
\hline Other & $5.5(0.3)$ & $7.1(0.6)$ \\
\hline \multicolumn{3}{|l|}{ Education level } \\
\hline$<$ High school & $5.4(0.2)$ & $4.3(0.3)$ \\
\hline Some high school & $9.7(0.3)$ & $8.9(0.6)$ \\
\hline High school graduate & $32.8(0.5)$ & $30.2(0.9)$ \\
\hline Some college & $23.6(0.4)$ & $22.7(0.8)$ \\
\hline College graduate & $28.4(0.6)$ & $34.0(1.1)$ \\
\hline \multicolumn{3}{|l|}{$\begin{array}{l}\text { Household income level } \\
\quad(\% \text { FPL })\end{array}$} \\
\hline$<100$ & $7.8(0.3)$ & $7.8(0.5)$ \\
\hline $100-124$ & $3.4(0.2)$ & $3.5(0.3)$ \\
\hline $125-199$ & $12.0(0.4)$ & $11.3(0.6)$ \\
\hline $200-399$ & $30.0(0.5)$ & $30.4(0.9)$ \\
\hline$\geq 400$ & $46.8(0.7)$ & $47.0(1.1)$ \\
\hline \multicolumn{3}{|l|}{ Census region } \\
\hline Northeast & $24.5(1.0)$ & $25.8(1.4)$ \\
\hline Midwest & $22.0(1.0)$ & $21.1(1.3)$ \\
\hline South & $37.0(1.1)$ & $34.6(1.4)$ \\
\hline West & $16.5(1.0)$ & $18.5(1.5)$ \\
\hline Urbanicity (residence in MSA) & $82.8(1.0)$ & $88.5(1.0)$ \\
\hline \multicolumn{3}{|l|}{ Health insurance } \\
\hline Private & $78.2(0.5)$ & $79.9(0.8)$ \\
\hline Public & $15.9(0.4)$ & $14.8(0.7)$ \\
\hline None & $5.9(0.2)$ & $5.2(0.4)$ \\
\hline \multicolumn{3}{|l|}{ Health status (SF-12) } \\
\hline $\begin{array}{l}\text { Physical Component Summary } \\
\text { score }\end{array}$ & $48.1(0.13)$ & $49.0(0.23)$ \\
\hline $\begin{array}{l}\text { Mental Component Summary } \\
\text { score }\end{array}$ & $51.2(0.10)$ & $50.5(0.19)$ \\
\hline \multicolumn{3}{|l|}{ Self-rated health } \\
\hline Excellent & $22.8(0.4)$ & $23.6(0.8)$ \\
\hline Very good & $33.9(0.5)$ & $34.1(0.9)$ \\
\hline Good & $27.9(0.4)$ & $28.3(0.9)$ \\
\hline Fair & $11.3(0.3)$ & $10.5(0.5)$ \\
\hline Poor & $4.1(0.2)$ & $3.5(0.3)$ \\
\hline Chronic health conditions* & $1.09(0.01)$ & $1.00(0.02)$ \\
\hline
\end{tabular}

Continued
Table 1. Continued

\begin{tabular}{lcc}
\hline & \multicolumn{2}{c}{ Gender of the USOC } \\
\cline { 2 - 3 } Characteristics & $\begin{array}{c}\text { Male } \\
(\mathrm{n}=16,896)\end{array}$ & $\begin{array}{c}\text { Female } \\
(\mathrm{n}=4469)\end{array}$ \\
\hline Body mass index $\left(\mathrm{kg} / \mathrm{m}^{2}\right)$ & & \\
$\quad<20$ & $4.9(0.2)$ & $6.0(0.4)$ \\
$20-<25$ & $29.9(0.4)$ & $32.7(0.9)$ \\
$25-<30$ & $36.6(0.4)$ & $32.7(0.8)$ \\
$\geq 30$ & $28.5(0.4)$ & $28.7(0.9)$ \\
Smoker & $18.3(0.4)$ & $16.3(0.7)$ \\
Skepticism toward medical care & $1.93(0.01)$ & $1.91(0.02)$ \\
Survey panel year & & \\
2002 & $14.3(0.5)$ & $11.8(0.7)$ \\
2003 & $15.7(0.5)$ & $12.8(0.7)$ \\
2004 & $14.3(0.4)$ & $14.6(0.8)$ \\
2005 & $14.4(0.5)$ & $13.1(0.7)$ \\
2006 & $13.4(0.4)$ & $15.4(0.8)$ \\
2007 & $10.5(0.5)$ & $10.9(0.9)$ \\
2008 & $17.3(0.7)$ & $21.4(1.2)$ \\
USOC characteristics & & \\
Specialty & & \\
Family medicine/general & & \\
practice & & \\
General internal medicine & $22.6(0.6)$ & $25.3(1.1)$ \\
Subspecialty & $4.0(0.2)$ & $2.8(0.3)$ \\
Non-Hispanic white & & \\
\hline
\end{tabular}

Values are provided as mean percentage (standard error). Percentages are population-weighted.

*From a count of 8 conditions: diabetes, hypertension, coronary heart disease, myocardial infarction, cerebrovascular disease, asthma, emphysema, and arthritis.

FPL, Federal Poverty Level; MSA, metropolitan statistical area, SF-12, 12-item Short Form.

a general internist or subspecialist (vs family physician/general practitioner) was associated with higher total health care expenditures, although the association was statistically significant for only general internists. However, female USOC status was not associated with total expenditures.

Regarding prescription drug expenditures, office visits, emergency department use, and hospital use, a number of patient characteristics were associated with these outcomes, and USOC specialty was associated with office visits (more visits for general internists) and prescription drug expenditures (higher expenditures for general internists and subspecialists) (data not shown but available upon request). However, female USOC status was not significantly associated with any of these usage outcomes (APE for prescription drug expenditures $=3.33,95 \%$ confidence interval $[\mathrm{CI}],-4.32$ to 11.59 ; APE for office visits $=1.28,95 \% \mathrm{CI}$, 
Table 2. Adjusted Associations of Patient and Usual Source of Care (USOC) Characteristics with Female USOC $(\mathrm{N}=21,365)$

\begin{tabular}{|c|c|c|}
\hline & AOR (95\% CI) & $P$ \\
\hline \multicolumn{3}{|l|}{ Patient characteristics } \\
\hline Age, per 10 years & $0.90(0.87-0.93)$ & $<.001$ \\
\hline Female & $2.48(2.28-2.70)$ & $<.001$ \\
\hline \multicolumn{3}{|l|}{ Race/ethnicity } \\
\hline Non-Hispanic white & Reference & \\
\hline Hispanic (any race) & $0.93(0.80-1.09)$ & .36 \\
\hline Non-Hispanic black & $1.07(0.92-1.24)$ & .40 \\
\hline Non-Hispanic other & $0.99(0.80-1.23)$ & .96 \\
\hline \multicolumn{3}{|l|}{ Education level } \\
\hline$<$ High school & Reference & \\
\hline Some high school & $1.08(0.86-1.35)$ & .52 \\
\hline High school graduate & $1.03(0.85-1.25)$ & .78 \\
\hline Some college & $1.01(0.82-1.25)$ & .91 \\
\hline College graduate & $1.29(1.05-1.60)$ & .02 \\
\hline \multicolumn{3}{|l|}{$\begin{array}{l}\text { Household income level, \% } \\
\text { FPL }\end{array}$} \\
\hline$<100$ & Reference & \\
\hline $100-124$ & $1.04(0.81-1.33)$ & .76 \\
\hline $125-199$ & $0.99(0.82-1.21)$ & .95 \\
\hline $200-399$ & $1.04(0.87-1.24)$ & .69 \\
\hline$\geq 400$ & $1.01(0.84-1.21)$ & .93 \\
\hline \multicolumn{3}{|l|}{ Census region } \\
\hline Northeast & Reference & \\
\hline Midwest & $0.95(0.80-1.13)$ & .58 \\
\hline South & $0.93(0.81-1.07)$ & .29 \\
\hline West & $1.10(0.92-1.30)$ & .29 \\
\hline Urbanicity (residence in MSA) & $1.43(1.23-1.66)$ & $<.001$ \\
\hline \multicolumn{3}{|l|}{ Health insurance } \\
\hline Private & Reference & \\
\hline Public & $0.97(0.85-1.11)$ & .69 \\
\hline None & $0.88(0.73-1.08)$ & .22 \\
\hline \multicolumn{3}{|l|}{ Health status (SF-12) } \\
\hline $\begin{array}{l}\text { Physical Component } \\
\text { Summary score }\end{array}$ & $1.00(1.00-1.01)$ & .18 \\
\hline $\begin{array}{l}\text { Mental Component } \\
\text { Summary score }\end{array}$ & $1.00(0.99-1.00)$ & .28 \\
\hline \multicolumn{3}{|l|}{ Self-rated health } \\
\hline Excellent & Reference & \\
\hline Very good & $0.97(0.87-1.09)$ & .66 \\
\hline Good & $1.04(0.91-1.18)$ & .60 \\
\hline Fair & $1.03(0.85-1.25)$ & .77 \\
\hline Poor & $1.01(0.76-1.33)$ & .96 \\
\hline Chronic health conditions* & $1.02(0.97-1.06)$ & .44 \\
\hline \multicolumn{3}{|l|}{ Body mass index $\left(\mathrm{kg} / \mathrm{m}^{2}\right)$} \\
\hline$<20$ & Reference & \\
\hline $20-<25$ & $1.01(0.84-1.23)$ & .88 \\
\hline $25-<30$ & $1.02(0.83-1.24)$ & .87 \\
\hline$\geq 30$ & $1.06(0.86-1.30)$ & .58 \\
\hline
\end{tabular}

Continued
Table 2. Continued

\begin{tabular}{lcc}
\hline & AOR $(95 \%$ CI $)$ & $P$ \\
\hline Smoker & $0.93(0.82-1.04)$ & .20 \\
$\begin{array}{l}\text { Skepticism toward medical } \\
\text { care }\end{array}$ & $1.01(0.96-1.07)$ & .65 \\
Survey panel year & $1.07(1.04-1.10)$ & $<.001$ \\
USOC characteristics & & \\
Specialty & & \\
$\quad$ Family medicine/general & & \\
$\quad$ practice & Reference & \\
$\quad$ General internal medicine & $1.12(0.98-1.28)$ & .10 \\
$\quad$ Subspecialty & $0.78(0.61-1.01)$ & .06 \\
Non-Hispanic white & $0.65(0.58-0.74)$ & $<.001$ \\
\hline
\end{tabular}

*From a count of 8 conditions: diabetes, hypertension, coronary heart disease, myocardial infarction, cerebrovascular disease, asthma, emphysema, and arthritis.

AOR, adjusted odds ratio; CI, confidence interval; FPL, Federal Poverty Level; MSA, metropolitan statistical area; SF-12, 12item Short Form.

-3.30 to 6.08 ; adjusted odds ratio for emergency department use $=0.98,95 \%$ CI, 0.87-1.11; adjusted odds ratio for hospital use $=0.98,95 \%$ CI, $0.87-1.11)$.

\section{Associations of Year 1 Patient and USOC Characteristics With Mortality}

Table 5 shows the results of analyses examining adjusted associations of patient and USOC characteristics with all-cause mortality. Patient characteristics predicting increased mortality were increasing age, non-Hispanic black race/ethnicity, having fair or poor self-rated health, and smoking. Patient predictors of decreased mortality were being female, having any BMI above the $<20 \mathrm{~kg} / \mathrm{m}^{2}$ category, and higher physical health status. USOC characteristics, including female gender, did not predict mortality.

\section{Supplementary Analyses}

In regression analyses limited to respondents reporting the same USOC gender in both survey participation years but employing the same covariates as in the primary models, there were no significant associations of female USOC gender with any of the health care usage measures or with mortality. In "difference in differences" analyses examining the associations of change in usage associated with change in USOC gender between survey participation years, change in USOC gender was not associated with changes in any of the health care 
Table 3. Patient Healthcare Utilization in Year 2 by Gender of Usual Source of Care (USOC) in Year 1

$(\mathrm{N}=21,365)$

\begin{tabular}{lccc}
\hline & \multicolumn{2}{c}{ Gender of USOC } \\
\cline { 2 - 3 } Utilization variable & Male (n=16,896) & Female $(\mathrm{n}=4,469)$ & 20.9 \\
\hline Percentage of total & 79.1 & $5.15(0.22)$ & .52 \\
Total healthcare expenditures (thousands of dollars) & $5.32(0.12)$ & $1.20(0.04)$ & .49 \\
Prescription drug expenditures (thousands of dollars) & $1.24(0.02)$ & $5.05(0.12)$ & .73 \\
Office visits, $\mathrm{n}$ & $5.09(0.07)$ & $14.6(0.6)$ & .49 \\
Any emergency department visit, \% & $15.1(0.4)$ & $10.1(0.5)$ & .19 \\
Any hospitalization, \% & $10.9(0.3)$ & & \\
\hline
\end{tabular}

Values provided as means (standard error). Percentages are population weighted.

usage measures (data not shown but available upon request).

\section{Discussion}

Prior studies demonstrating practice style differences between female and male providers suggested the possibility that provider gender might be independently associated with patient health care use and mortality. However, our study is the first to address these questions. In prospective analyses of data from a national sample of U.S. adults, adjusted for patient and USOC characteristics associated with health care use and mortality, we found no evidence of independent associations between USOC gender in a baseline year and total health care or prescription drug expenditures, hospital or emergency department use, or office visits in the subsequent year. We also found no significant association between USOC gender and subsequent mortality. Supplementary analyses limited to respondents reporting the same USOC gender both years and another set examining the change in use associated with a change in USOC gender yielded consistent findings. These findings suggest practice styles associated with USOC gender are unlikely to have an effect on health care use or mortality.

Our analyses did find associations between female USOC and some patient characteristics (younger age, female gender, college education, and urban residence) and with secular changes (more recent panels). These findings emphasize the importance of adjusting for such patient characteristics in studies examining the effects of provider gender on the process of care. In addition, female USOCs were more likely to be of nonwhite race than male USOCs, underscoring how female pro- viders are contributing to greater diversity in the health care provider workforce.

While our study was not designed to determine the specific mechanisms of our findings, at least 2 explanations seem plausible. The first is that the more optimal interpersonal communication behaviors and process of care outcomes previously observed among female USOCs do not translate into measurable effects on health care use and mortality. The second is that the communication behaviors and process of care tendencies of female USOCs, and the care-seeking proclivities of patients who choose female providers, may have complex, sometimes competing influences on use and mortality. Such competing influences, which may be partly dependent on the specific clinical context, could result in no significant net effect of female USOC on these outcomes, at least when examined in a broadly representative sample. Future research designed to study the contributions of these and other potential mechanisms of our findings may be useful. Nonetheless, our findings are likely to closely reflect the net associations of USOC gender with the studied usage outcomes and mortality at a national level. As such, they may have relevance to health educators and policy makers.

Our study had some limitations. While our findings suggest possible causal relationships, they are not firmly established or "proven" by our observational (albeit prospective) analyses, requiring cautious interpretation. Analyses were limited to MEPS respondents reporting a usual source of care and participating for 2 years, so our findings may not be applicable to other kinds of patients and outcomes. Many prior studies examining the association of physician gender with process of care 
Table 4. Adjusted Associations of Patient and Usual Source of Care (USOC) Characteristics in Year 1 With Total Expenditures in Year $2(\mathrm{~N}=21,365)$

\begin{tabular}{|c|c|c|}
\hline & Adjusted $\mathrm{PE}^{*}(95 \% \mathrm{CI})$ & $P$ \\
\hline \multicolumn{3}{|l|}{ Patient characteristics } \\
\hline Age, per 10 years & $16.43(13.58-19.36)$ & $<.001$ \\
\hline Female & $1.57(-5.22$ to 8.86$)$ & .66 \\
\hline \multicolumn{3}{|l|}{ Race/ethnicity } \\
\hline Non-Hispanic white & Reference & \\
\hline Hispanic (any race) & $-11.55(-21.13$ to -0.80$)$ & .04 \\
\hline Non-Hispanic black & $6.48(-6.05$ to 20.68$)$ & .32 \\
\hline Non-Hispanic other & $-21.81(-31.24$ to -11.08$)$ & $<.001$ \\
\hline \multicolumn{3}{|l|}{ Education level } \\
\hline$<$ High school & Reference & \\
\hline Some high school & $5.44(-6.81$ to 19.29$)$ & .40 \\
\hline $\begin{array}{l}\text { High school } \\
\text { graduate }\end{array}$ & $10.14(-1.79$ to 23.53$)$ & .10 \\
\hline Some college & $23.33(8.60-40.06)$ & .001 \\
\hline College graduate & $39.51(22.04-59.49)$ & $<.001$ \\
\hline \multicolumn{3}{|l|}{$\begin{array}{c}\text { Household income } \\
\text { level, \% FPL }\end{array}$} \\
\hline$<100$ & Reference & \\
\hline $100-124$ & $-5.72(-19.98$ to 11.08$)$ & .48 \\
\hline $125-199$ & $-1.85(-15.05$ to 13.40$)$ & .80 \\
\hline $200-399$ & $-5.99(-15.68$ to 4.81$)$ & .26 \\
\hline$\geq 400$ & $-1.19(-11.82$ to 10.72$)$ & .84 \\
\hline \multicolumn{3}{|l|}{ Census region } \\
\hline Northeast & Reference & \\
\hline Midwest & $5.48(-5.41$ to 17.62$)$ & .34 \\
\hline South & $-9.27(-18.28$ to 0.72$)$ & .07 \\
\hline West & $8.45(-4.52$ to 23.19$)$ & .21 \\
\hline $\begin{array}{l}\text { Urbanicity (residence } \\
\text { in MSA) }\end{array}$ & $-0.92(-9.07$ to 7.95$)$ & .83 \\
\hline \multicolumn{3}{|l|}{ Health insurance } \\
\hline Private & Reference & \\
\hline Public & $-9.23(-16.47$ to -1.37$)$ & .02 \\
\hline None & $-45.18(-52.66$ to -36.52$)$ & $<.001$ \\
\hline \multicolumn{3}{|l|}{ Health status (SF-12) } \\
\hline $\begin{array}{l}\text { Physical Component } \\
\text { Summary score }\end{array}$ & $-2.06(-2.54$ to -1.58$)$ & $<.001$ \\
\hline $\begin{array}{l}\text { Mental Component } \\
\text { Summary score }\end{array}$ & $-0.70(-1.06$ to -0.34$)$ & $<.001$ \\
\hline \multicolumn{3}{|l|}{ Self-rated health } \\
\hline Excellent & Reference & \\
\hline Very good & $12.98(3.49-23.34)$ & .006 \\
\hline Good & $27.68(15.53-41.10)$ & $<.001$ \\
\hline Fair & $60.99(33.36-94.33)$ & $<.001$ \\
\hline Poor & $94.10(60.45-134.82)$ & $<.001$ \\
\hline $\begin{array}{l}\text { Chronic health } \\
\text { conditions }^{\dagger}\end{array}$ & $15.73(11.65-19.96)$ & $<.001$ \\
\hline
\end{tabular}

Continued
Table 4. Continued

\begin{tabular}{lcc}
\hline & Adjusted PE* $(95 \%$ CI $)$ & $P$ \\
\hline $\begin{array}{c}\text { Body mass index } \\
\left(\mathrm{kg} / \mathrm{m}^{2}\right)\end{array}$ & Reference & \\
$<20$ & $7.17(-9.91$ to 27.49$)$ & .43 \\
$20-<25$ & $2.23(-15.01$ to 22.98$)$ & .82 \\
$25-<30$ & $8.40(-8.82$ to 28.87$)$ & .36 \\
$\geq 30$ & $1.59(-7.51$ to 11.57$)$ & .74 \\
Smoker & & \\
Skepticism toward & $11.26(-15.28$ to -7.06$)$ & $<.001$ \\
medical care & $3.46(1.62-5.34)$ & $<.001$ \\
Survey panel year & & \\
& & \\
USOC characteristics & & \\
Specialty & Reference & \\
Family medicine/ & & .001 \\
general practice & $15.25(5.94-25.38)$ \\
General internal & $11.77(-1.46$ to 26.76$)$ & .08 \\
$\quad$ medicine & $3.93(-4.13$ to 12.66$)$ & .35 \\
Subspecialty & $4.56(-3.04$ to 12.76$)$ & .25 \\
Non-Hispanic white & & \\
Female & & \\
& &
\end{tabular}

*Adjusted parameter estimate $(\mathrm{PE})$ is from a Poisson regression and represents the percent change in outcome per unit change in predictor variable.

${ }^{\dagger}$ From a count of 8 conditions: diabetes, hypertension, coronary heart disease, myocardial infarction, cerebrovascular disease, asthma, emphysema, and arthritis.

CI, confidence interval; FPL, Federal Poverty Level; MSA, metropolitan statistical area; SF-12, 12-item Short Form.

have linked physician gender with specific visits. By contrast, our analyses examined the net association of USOC gender with health care use and mortality, with no information about how much care respondents actually received from their USOC.

Although we examined a range of usage outcomes as well as mortality, it is uncertain whether similar findings would be observed for other types of health care use and outcomes. All our study measures (other than mortality) were based on respondent self-report, raising the possibility that the findings could have been affected by misreporting bias. However, misreporting of USOC gender, the key independent variable, was likely to be infrequent. We also lacked information regarding some USOC characteristics (eg, age) and patient characteristics (eg, length of time with the current $\mathrm{USOC}^{46}$ ) that may influence various aspects of health care delivery, although with uncertain net effects on health care use and mortality. Survey nonresponse was also a potential problem. While the MEPS weighting attempts to adjust for nonre- 
Table 5. Adjusted Associations of Patient and Usual Source of Care (USOC) Characteristics in Year 1 With All-Cause Mortality in Year $2(\mathrm{~N}=11,328)$

\begin{tabular}{|c|c|c|}
\hline & $\begin{array}{l}\text { Adjusted HR* } \\
\quad(95 \% \mathrm{CI})\end{array}$ & $P$ \\
\hline \multicolumn{3}{|l|}{ Patient characteristics } \\
\hline Age, per 10 years & $2.39(2.08-2.76)$ & $<.001$ \\
\hline Female & $0.51(0.38-0.69)$ & $<.001$ \\
\hline \multicolumn{3}{|l|}{$\begin{array}{l}\text { Race/ethnicity (ref }= \\
\text { Non-Hispanic white) }\end{array}$} \\
\hline Non-Hispanic white & Reference & \\
\hline Hispanic (any race) & $0.64(0.41-1.01)$ & .05 \\
\hline Non-Hispanic black & $1.56(1.01-2.39)$ & .04 \\
\hline Non-Hispanic other & $0.87(0.35-2.16)$ & .77 \\
\hline \multicolumn{3}{|l|}{ Education level } \\
\hline$<$ High school & Reference & \\
\hline Some high school & $1.03(0.69-1.55)$ & .88 \\
\hline High school graduate & $0.78(0.51-1.19)$ & .24 \\
\hline Some college & $1.20(0.71-2.02)$ & .50 \\
\hline College graduate & $0.66(0.41-1.07)$ & .09 \\
\hline \multicolumn{3}{|l|}{$\begin{array}{l}\text { Household income level, \% } \\
\text { FPL (ref <100\%) }\end{array}$} \\
\hline$<100 \%$ & Reference & \\
\hline $100-124$ & $1.57(0.90-2.75)$ & .11 \\
\hline $125-199$ & $1.29(0.85-1.98)$ & .23 \\
\hline $200-399$ & $1.32(0.89-1.95)$ & .16 \\
\hline$\geq 400$ & $1.45(0.92-2.30)$ & .11 \\
\hline \multicolumn{3}{|l|}{ Census region } \\
\hline Northeast & Reference & \\
\hline Midwest & $0.85(0.54-1.34)$ & .48 \\
\hline South & $1.03(0.74-1.43)$ & .86 \\
\hline West & $1.26(0.85-1.89)$ & .25 \\
\hline $\begin{array}{l}\text { Urbanicity (residence in } \\
\text { MSA) }\end{array}$ & $0.94(0.68-1.30)$ & .71 \\
\hline \multicolumn{3}{|l|}{ Health insurance } \\
\hline Private & Reference & \\
\hline Public & $0.94(0.70-1.26)$ & .67 \\
\hline None & $0.64(0.26-1.57)$ & .33 \\
\hline \multicolumn{3}{|l|}{ Health status (SF-12) } \\
\hline $\begin{array}{l}\text { Physical Component } \\
\text { Summary score }\end{array}$ & $0.97(0.96-0.98)$ & $<.001$ \\
\hline $\begin{array}{l}\text { Mental Component } \\
\text { Summary score }\end{array}$ & $0.99(0.97-1.00)$ & .11 \\
\hline \multicolumn{3}{|l|}{ Self-rated health } \\
\hline Excellent & Reference & \\
\hline Very good & $1.25(0.73-2.17)$ & .42 \\
\hline Good & $1.42(0.85-2.37)$ & .17 \\
\hline Fair & $2.01(1.13-3.59)$ & .02 \\
\hline Poor & $2.46(1.26-4.83)$ & .01 \\
\hline Chronic health conditions* & $1.06(0.95-1.18)$ & .31 \\
\hline
\end{tabular}

Continued
Table 5. Continued

\begin{tabular}{lcc}
\hline & $\begin{array}{c}\text { Adjusted HR* } \\
(95 \% \mathrm{CI})\end{array}$ & $P$ \\
\hline $\begin{array}{c}\text { Body mass index }\left(\mathrm{kg} / \mathrm{m}^{2}\right) \\
\quad\end{array}$ & Reference & \\
$\quad<20$ & $0.35(0.23-0.53)$ & $<.001$ \\
$20-<25$ & $0.21(0.14-0.33)$ & $<.001$ \\
$25-<30$ & $0.21(0.12-0.36)$ & $<.001$ \\
$\geq 30$ & $1.68(1.16-2.46)$ & .01 \\
Smoker & & \\
Skepticism toward medical & $0.93(0.76-1.13)$ & .44 \\
$\quad$ care & $1.14(0.96-1.36)$ & .13 \\
Survey panel year & & \\
USOC characteristics & & \\
Specialty (ref = family & & \\
$\quad$ medicine/general & & \\
practice $)$ & & .47 \\
Family medicine/general & & .39 \\
$\quad$ practice & & \\
General internal & & \\
$\quad$ medicine & $1.13(0.81-1.56)$ & .76 \\
Subspecialty & $1.58(0.92-2.71)$ & .10 \\
Non-Hispanic white & $0.86(0.61-1.21)$ & .39 \\
Female & $0.94(0.64-1.38)$ & \\
\hline$\quad$ & & \\
\hline
\end{tabular}

*Adjusted hazard ratio (HR) is from a Cox proportional hazards regression limited to respondents enrolled from 2002-2006 (since National Death Index mortality data was available only through December 31, 2006).

${ }^{\dagger}$ From a count of 8 conditions: diabetes, hypertension, coronary heart disease, myocardial infarction, cerebrovascular disease, asthma, emphysema, and arthritis.

CI, confidence interval; FPL, Federal Poverty Level; HR, hazard ratio; MSA, metropolitan statistical area; SF-12, 12-item Short Form.

sponse, uncertainty remains about extension of the findings to nonresponders. However, the MEPS (and NDI) likely offer the most representative data available to examine the issues explored here.

\section{Conclusion}

In adjusted analyses of prospective data from a large U.S. sample, the gender of the USOC was not associated with measures of health care use (total and prescription drug expenditures, emergency department and hospital use, office visits) or mortality. These findings suggest that USOC gender may not have important effects on health care use and mortality at a national level.

\section{References}

1. Bernzweig J, Takayama JI, Phibbs C, Lewis C, Pantell RH. Gender differences in physician-patient communication. Evidence from pediatric visits. Arch Pediatr Adolesc Med 1997;151:586-91. 
2. Bertakis KD, Helms LJ, Callahan EJ, Azari R, Robbins JA. The influence of gender on physician practice style. Med Care 1995;33:407-16.

3. Roter DL, Hall JA. Physician gender and patientcentered communication: a critical review of empirical research. Annu Rev Public Health 2004;25:497519.

4. Bertakis KD, Franks P, Epstein RM. Patient-centered communication in primary care: physician and patient gender and gender concordance. J Womens Health (Larchmt) 2009;18:539-45.

5. Bertakis KD, Azari R. Patient-centered care is associated with decreased health care utilization. J Am Board Fam Med 2011;24:229-39.

6. Epstein RM, Franks P, Shields CG, et al. Patientcentered communication and diagnostic testing. Ann Fam Med 2005;3:415-21.

7. Bertakis KD, Azari R. Patient-centered care: the influence of patient and resident physician sex and gender concordance in primary care. J Womens Health (Larchmt) 2012;21:326-33.

8. Franks P, Bertakis KD. Physician gender, patient gender, and primary care. J Womens Health (Larchmt) 2003;12:73-80.

9. Andersen MR, Urban N. Physician gender and screening: do patient differences account for differences in mammography use? Women Health 1997; 26:29-39.

10. Franks P, Clancy CM. Physician gender bias in clinical decisionmaking: screening for cancer in primary care. Med Care 1993;31:213-8.

11. Lurie N, Slater J, McGovern P, Ekstrum J, Quam L, Margolis K. Preventive care for women. Does the gender of the physician matter? N Engl J Med 1993; 329:478-82.

12. Berthold HK, Gouni-Berthold I, Bestehorn KP, Bohm M, Krone W. Physician gender is associated with the quality of type 2 diabetes care. J Intern Med 2008;264:340-50.

13. Baumhakel M, Muller U, Bohm M. Influence of gender of physicians and patients on guideline-recommended treatment of chronic heart failure in a cross-sectional study. Eur J Heart Fail 2009;11:299303.

14. Kim C, McEwen LN, Gerzoff RB, et al. Is physician gender associated with the quality of diabetes care? Diabetes Care 2005;28:1594-8.

15. Cost effectiveness analysis of improved blood pressure control in hypertensive patients with type 2 diabetes: UKPDS 40. UK Prospective Diabetes Study Group. BMJ 1998;317:720-6.

16. Shibata MC, Flather MD, Wang D. Systematic review of the impact of beta blockers on mortality and hospital admissions in heart failure. Eur J Heart Fail 2001;3:351-7.

17. McAlister FA, Wiebe N, Ezekowitz JA, Leung AA, Armstrong PW. Meta-analysis: beta-blocker dose, heart rate reduction, and death in patients with heart failure. Ann Intern Med 2009;150:784-94.

18. Bangalore S, Kumar S, Lobach I, Messerli FH. Blood pressure targets in subjects with type 2 diabetes mellitus/impaired fasting glucose: observations from traditional and bayesian random-effects metaanalyses of randomized trials. Circulation 2011;123: 2799-810.

19. Medical Expenditure Panel Survey. Rockville, MD: Agency for Healthcare Research and Quality. Available from: http://www.meps.ahrq.gov/mepsweb/about meps/survey_back.jsp. Accessed March 3, 2012.

20. NHIS linked mortality public use files. Available from: http://www.cdc.gov/nchs/data_access/data_linkage/ mortality/nhis_linkage_public_use.htm. Accessed March 3, 2012.

21. Bertakis KD, Azari R. Obesity and the use of health care services. Obes Res 2005;13:372-9.

22. Bertakis KD, Azari R. The influence of obesity, alcohol abuse, and smoking on utilization of health care services. Fam Med 2006;38:427-34.

23. Fiscella K, Franks P, Clancy CM. Skepticism toward medical care and health care utilization. Med Care 1998;36:180-9.

24. Fiscella K, Franks P, Clancy CM, Doescher MP, Banthin JS. Does skepticism towards medical care predict mortality? Med Care 1999;37:409-14

25. Muennig P, Lubetkin E, Jia H, Franks P. Gender and the burden of disease attributable to obesity. Am J Public Health 2006;96:1662-8.

26. DeSalvo KB, Fan VS, McDonell MB, Fihn SD. Predicting mortality and healthcare utilization with a single question. Health Serv Res 2005;40:1234-46.

27. Franks P, Gold MR, Fiscella K. Sociodemographics, self-rated health, and mortality in the US. Soc Sci Med 2003;56:2505-14.

28. Fiscella K, Franks P. Individual income, income inequality, health, and mortality: what are the relationships? Health Serv Res 2000;35:307-18.

29. Franks P, Fiscella K. Effect of patient socioeconomic status on physician profiles for prevention, disease management, and diagnostic testing costs. Med Care 2002;40:717-24.

30. Franks P, Muennig P, Lubetkin E, Jia H. The burden of disease associated with being African-American in the United States and the contribution of socio-economic status. Soc Sci Med 2006;62:2469-78.

31. Probst JC, Bellinger JD, Walsemann KM, Hardin J, Glover SH. Higher risk of death in rural blacks and whites than urbanites is related to lower incomes, education, and health coverage. Health Aff (Milwood) 2011;30:1872-9.

32. Remler DK, Teresi JA, Weinstock RS, et al. Health care utilization and self-care behaviors of Medicare beneficiaries with diabetes: comparison of national and ethnically diverse underserved populations. Popul Health Manag 2011;14:11-20. 
33. Rosenthal T. Geographic variation in health care. Annu Rev Med 2012;63:493-509.

34. Cullen MR, Cummins C, Fuchs VR. Geographic and racial variation in premature mortality in the U.S.: analyzing the disparities. PloS One 2012;7: e32930.

35. Ward L, Franks P. Changes in health care expenditure associated with gaining or losing health insurance. Ann Intern Med 2007;146:768-74.

36. Thorpe RJ Jr, Koster A, Bosma H, et al. Racial differences in mortality in older adults: factors beyond socioeconomic status. Ann Behav Med 2012; 43:29-38.

37. Borrell LN, Lancet EA. Race/ethnicity and all-cause mortality in US adults: revisiting the Hispanic paradox. Am J Public Health 2012;102:836-43.

38. Bustamante AV, Chen J. Health expenditure dynamics and years of U.S. residence: analyzing spending disparities among Latinos by citizenship/nativity status. Health Serv Res 2012;47:794-818.

39. Ware J Jr, Kosinski M, Keller SD. A 12-item ShortForm Health Survey: construction of scales and preliminary tests of reliability and validity. Med Care 1996;34:220-33.
40. Bertakis KD, Robbins JA. Gatekeeping in primary care: a comparison of internal medicine and family practice. J Fam Pract 1987;24:305-9.

41. Bertakis KD, Robbins JA. Utilization of hospital services. A comparison of internal medicine and family practice. J Fam Pract 1989;28:91-6.

42. LaVeist TA, Nuru-Jeter A, Jones KE. The association of doctor-patient race concordance with health services utilization. J Public Health Policy 2003;24: $312-23$

43. Fenton JJ, Jerant AF, Bertakis KD, Franks P. The cost of satisfaction: a national study of patient satisfaction, health care utilization, expenditures, and mortality. Arch Intern Med 2012;172:405-11.

44. Hsiao C. Analysis of Panel Data. 2nd ed. Cambridge, NY: Cambridge University Press; 2003.

45. Wooldridge JM. Econometric Analysis of Cross Section and Panel Data. 2nd ed. Cambridge, MA: MIT Press; 2010.

46. Hjortdahl P, Borchgrevink CF. Continuity of care: influence of general practitioners' knowledge about their patients on use of resources in consultations. BMJ 1991;303:1181-4. 